\title{
A incubação da extrema-direita: a rede de financiamento do PSL nas eleições de 2018
}

Artigos Originais

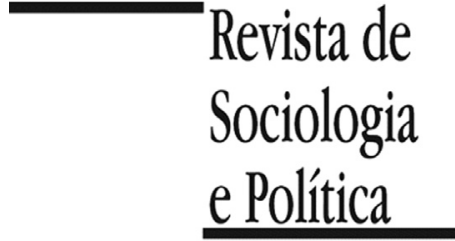

DOI 10.1590/1678-987321297805

\author{
Rodolfo Palazzo Dias'(iD, Rodrigo Mayer" \\ ${ }^{1}$ Programa de Pós-Graduação em Sociologia e Antropologia, Universidade Federal do Rio deJaneiro, Rio de Janeiro, RJ, Brasil. \\ ${ }^{2}$ Departamento de Educação, Universidade Estadual de Ponta Grossa, Ponta Grossa, PR, Brasil.
}

Palavras-chave: Bolsonaro; extrema direita; partidos; financiamento de campanha; redes sociais.

\begin{abstract}
RESUMO Introdução: O artigo analisa a rede de receitas das campanhas eleitorais do Partido Social Liberal (PSL) no ano de 2018. Considerando o destacado sucesso desse partido no processo eleitoral daquele ano, eleger como objeto de estudo as campanhas do partido que obteve o cargo majoritário do executivo federal se justifica. Materiais e métodos: Mobilizamos a Análise de Redes Sociais para analisar os dados de receitas fornecidos pelos candidatos e órgãos partidários vinculados ao PSL para o Tribunal Superior Eleitoral e, ao fazê-lo, mapeamos a complexa rede de relações financeiras estabelecidas entre os agentes mobilizados na campanha daquele ano. Tal método permite a identificação de atores centrais dentro da rede, além dos agrupamentos nela formados. Resultados: O resultado empírico da pesquisa identifica índices significativos de sucesso eleitoral em situações de menor volume financeiro, corroborando com a interpretação do papel de destaque que os aspectos ideológicos tiveram nas eleições de 2018; além de identificar o destacamento da campanha presidencial em relação aos órgãos partidários. Discussão: Foi possível problematizar as condições de sucesso eleitoral em uma conjuntura política tão excepcional, assim como visualizar características da extrema-direita nessa conjuntura.
\end{abstract}

Recebido em 9 de Outubro de 2020. Aprovado em 10 de Junho de 2021. Aceito em 21 de Junho de 2021.

\section{Introduçãó ${ }^{1}$}

\author{
1 Agradecemos aos \\ comentários e sugestões dos \\ pareceristas anônimos da \\ Revista de Sociologia e \\ Política, à CAPES e ao \\ Programa de Pós-graduação \\ em Sociologia e Antropologia \\ (PPGSA/UFRJ).
}

$\mathrm{O}$ Partido Social Liberal (PSL) tomou de assalto as eleições de 2018. Outrora um partido nanico, ou irrelevante no cenário político nacional nas eleições de 2014 obteve apenas uma cadeira na Câmara dos Deputados - apresentou um desempenho surpreendente, elegendo 52 deputados federais, 4 senadores, 3 governadores e o Presidente da República.

A agremiação, no entanto, carrega a pecha de partido de aluguel. Não é para menos. Em sua história, o PSL serviu como receptáculo para grupos que buscavam adentrar na arena política e/ou para lideranças que almejavam maior protagonismo. Ao utilizarmos o termo "incubadora" para caracterizar a legenda, sustentamos o aspecto descartável do partido. Ou seja, uma vez que o grupo encubado tenha atingido seus objetivos, ele poderá: a) abandonar a instituição, seja adentrando em outro partido, seja criando um novo; b) poderá, ainda, assumir o controle da instituição partidária, reconfigurando suas características.

Considerando a plausibilidade desse argumento, realizamos uma pesquisa empírica sobre o financiamento de campanha, a fim de verificar as formas de recebimento de recursos nas eleições de 2018, assim como a formação de agrupamentos derivados desse processo. Para isso, aplicamos a metodologia de Análise de Redes Sociais (ARS) aos dados de recursos financeiros presentes na prestação de contas dos candidatos e dos órgãos partidários do PSL nas eleições de 2018.

$\mathrm{O}$ artigo está estruturado da seguinte maneira, além desta introdução. $\mathrm{Na}$ seção II, tratamos do financiamento de campanha presente nos estudos eleitorais; na seção III, produzimos uma análise sobre a história do PSL; na seção IV, realizamos considerações acerca da metodologia de Análise de Redes Sociais (ARS) e sua aplicação aos dados selecionados em nossa pesquisa. Nas 
subseções IV.I e IV.II, desenvolvemos nossa análise das redes filtrando os “outsiders" e realizando análise de agrupamento (modularidade) na rede principal; por fim, na seção $\mathrm{V}$, traçamos considerações finais explorando a maneira em que os achados empíricos da presente pesquisa contribuem tanto para o campo de estudos de financiamento de campanha no Brasil, quanto para a caracterização do PSL como partido.

\section{O Financiamento eleitoral nos estudos partidários}

A relação entre dinheiro e política é antiga e tem atraído olhares dos cientistas políticos há algum tempo (Mancuso et al., 2018; Rubio, 2005; Scarrow, 2006). Até meados da década de 2000, contudo, o campo ocupou um papel secundário nos estudos partidários.

O crescimento dos estudos sobre financiamento vem com o maior acesso aos dados sobre as receitas partidárias. Os partidos políticos consistem em organizações extremamente fechadas em si (Duverger, 1970), fornecendo poucas - ou nenhuma - informações sobre seu funcionamento a observadores externos.

A ausência de informações por parte das agremiações impactou na forma como os estudos de financiamento foram inicialmente realizados. Inicialmente, o campo recorreu a estudos sobre as leis e demais dispositivos legais (e constitucionais) sobre o financiamento, de modo a obter informações sobre as fontes de receitas partidárias. No começo da década de 2000, o cenário se alterou com a publicação das fontes de receitas extraparlamentares e de campanha dos partidos políticos, o que permitiu ir além de estudos normativos ou meramente formais (Scarrow, 2007).

No Brasil, o cenário desenvolveu-se de modo semelhante, através de três linhas de pesquisas principais sobre financiamento partidário. O primeiro enfoque busca compreender a relação entre os gastos de campanha e o sucesso eleitoral, com os autores argumentando que existe uma forte relação entre gastos de campanha e votos (Cervi, 2010; Samuels, 2001; Mancuso \& Speck, 2014; Speck \& Mancuso, 2013). A segunda linha busca compreender quais são os ganhos que os financiadores possuem ao financiar campanhas (Mancuso, 2012; Speck, 2011). Por fim, a terceira vertente busca compreender os fatores que determinam as doações para os candidatos, tais como: partido político, posição do candidato em relação ao governo, magnitude dos distritos, etc. (Mancuso, 2012).

Com o aumento da publicidade dos dados a partir da década de 2000 e, em 2014, com a resolução 23.406/2014 do Tribunal Eleitoral Superior (TSE), que estabeleceu que os partidos necessitam declarar a origem e os destinos dos recursos recebidos e transferidos para os candidatos (Horochovski et al., 2016; Mancuso, 2015; Mancuso et al., 2018), percebe-se uma viabilidade cada vez maior de estudos empiricamente orientados sobre financiamento de campanha no Brasil, ainda que não contenha a realidade completa.

Até meados de 2015, a principal fonte de receita dos partidos políticos brasileiros provinha de doações de grandes grupos empresariais, mais especificamente de construtoras, bancos, grupos alimentícios, siderúrgicas, etc. (Carazza, 2018; Speck, 2007). A concentração do financiamento em algumas empresas e grupos econômicos pode levar a uma série de problemas como corrupção, desincentivo a participação de setores populares, aumento da desconfiança com a política, entre outros (Mancuso et al., 2018; Mancuso \& Speck., 2014; Speck, 2007). 
Dito isso, é importante questionar o porquê de as empresas contribuírem para o financiamento das campanhas. A bibliografia especializada argumenta que as principais motivações dos doadores são duas: 1) ideológica: os doadores buscam fomentar políticas e bens públicos, comportamento mais comum de pessoas físicas e; 2) pragmática: buscam recursos para suas atividades através de sua relação com o Estado, que constitui um importante local de negócios, mais praticado por empresários (Carazza, 2018; Claessens et al., 2008; McMenamin, 2012, 2013, 2019; Mancuso et al., 2021).

Com a proibição do financiamento empresarial pelo STF em 2015, os partidos políticos buscaram novas fontes de financiamento como o reforço do fundo partidário e do fundo eleitoral. Apesar da proibição, as doações de empresas permaneceram através de Caixa 2 e dos empresários como pessoas físicas. Por isso, nas pesquisas de financiamento eleitoral brasileiro de 2018, as empresas ficaram de fora ou ocultas nos dados oficiais, mas permanecem como atores políticos relevantes.

O resultado eleitoral de 2018 teve grande impacto nos partidos tradicionais, trazendo resultados surpreendentes. O PSL, até então, considerado como um partido nanico chacoalha o cenário político nacional com a conquista da segunda maior bancada da Câmara dos Deputados, várias cadeiras no senado, governos estaduais, e a Presidência da República. Este artigo estuda a rede de financiamento deste partido.

\section{PSL: Origem, desenvolvimento e aluguéis}

${ }^{2}$ Em 1990, outro partido com a mesma sigla PSL competiu com registro provisório - nas eleições legislativas. O Partido do Solidarismo Libertador não guarda relações com o atual PSL e foi fundado por dissidentes do PSC. Em 1992, o partido teve seu registro negado e, em 1995, o mesmo grupo fundou o PSN, que posteriormente alterou sua denominação para PHS e foi incorporado pelo Podemos em 2018.

3 Antes das eleições de 2018, na qual elegeu 52 deputados federais, o PSL nunca elegeu mais que um parlamentar federal, e nas eleições de 2006 não chegou a eleger um deputado federal.

${ }^{4}$ Luciano Bivar fundou em 1994 e desde então, salvo raros períodos, comandou o destino da legenda. $\mathrm{O}$, hoje, parlamentar também utilizou a sua posição como dirigente do Sport Clube do Recife como forma de alavancar sua carreira política e o seu partido.
O Partido Social Liberal (PSL) ${ }^{2}$ foi fundado em 1996, no final do primeiro processo de realinhamento do sistema partidário brasileiro, e obteve seu registro definitivo em 1998 (Mayer, 2018; Schmitt, 2000). Antes das eleições de 2018, o partido, quando mencionado pela bibliografia, era geralmente classificado no grupo dos pequenos partidos de direita devido ao seu fraco desempenho eleito$\mathrm{ral}^{3}$ e sua irrelevância na arena política brasileira.

As eleições de 2018 alteraram o status da legenda, de partido insignificante ou de pequeno porte - para uma das maiores bancadas do Congresso Nacional. Grosso modo, podemos argumentar que o PSL seria uma espécie de "novo" partido tardio, isso é, não seria um novo partido político de fato. Os "novos partidos" surgem em momentos de crise, alterações nas regras institucionais e/ou estratégia dos atores políticos (Kestler et al., 2013). Utilizamos o termo "novo partido tardio" devido a sua refundação bolsonarista, que aliada ao contexto de crise tanto econômica como política (de representação e dos partidos tradicionais), fez com que a legenda tenha impactado fortemente o sistema político nacional e alterado a dinâmica da disputa eleitoral.

Da mesma forma que muitos partidos brasileiros, os sociais liberais são uma legenda fundada e organizada por uma única liderança ${ }^{4}$ durante boa parte de sua existência. Tal aspecto do partido só se transforma em momentos no qual ele é "alugado" para outras forças políticas, como no processo eleitoral de 2018 quando Luciano Bivar cede a presidência do partido para o então aliado de Jair Bolsonaro, Gustavo Bebbiano.

Essa característica levanta questionamentos sobre a institucionalização do partido. Ou seja, a organização do PSL ganhou valor em si em detrimento dos interesses individuais? O posicionamento das primeiras lideranças molda a organização partidária, que faz com que as instituições desenvolvam interesses próprios, para além do posicionamento dos membros atuais? A resposta para isso é não. Devido a sua natureza fisiológica e de aluguel, os sociais liberais utilizam a baixa institucionalização como uma estratégia de sobrevivência. Ao 
${ }^{5}$ Os partidos de notáveis (quadros) são formações típicas do século XIX, caracterizadas por organizações frágeis e existentes somente durante $o$ período eleitoral, sem uma ideologia definida e com poucos membros, os quais têm grande peso no financiamento das campanhas (Duverger, 1970).

\footnotetext{
${ }^{6}$ O Livres é um movimento que se auto-intitula suprapartidário e liberal na economia e nos costumes. O movimento começou como uma tendência do MBL e, a partir de 2016, tornou-se um movimento separado.

${ }^{7}$ Bolsonaro em sua tentativa de viabilizar sua candidatura presidencial recorreu a uma série de trocas partidárias. Primeiro saiu do PP (Partido Progressista) em 2016 para o PSC. A estadia nos sociais cristãos foi curta e, em 2017, migrou para o PSL.

${ }^{8}$ Até o momento da redação deste artigo, o processo de formação da Aliança enfrenta uma série de problemas (principalmente na coleta de assinaturas) e uma reaproximação com o PSL não está descartada.
}

não fortalecer a sua organização, a agremiação almeja facilitar a atração de políticos ou grupos interessados em alugar o seu espaço.

A legenda durante boa parte de sua existência consistiu em um partido de aluguel, isto é, sem definição ideológica e a serviço dos interesses de seu proprietário, o qual negocia a legenda (ou os serviços dela) para políticos em busca de maior protagonismo eleitoral e/ou realiza negociações com outras legendas para obtenção de vantagens para as lideranças da legenda e, assim, garantir a sobrevivência do partido. Como muitos partidos fisiológicos brasileiros, a legenda também abre suas portas para abrigar dissidentes de outros partidos e/ou movimentos políticos - e sociais - a procura de alguma etiqueta que os abrigue para satisfazer seus objetivos eleitorais.

Este tipo de partido não tem grandes incentivos para o fortalecimento de suas organizações e da construção de uma linha programática clara, pois seus esforços estão concentrados na obtenção de recursos para auxiliar nas campanhas eleitorais de suas lideranças, como uma espécie de empreendimento.

A definição de partido de aluguel aproxima-se muito da tipologia de partidos clientelistas elaborada por Gunther e Diamond (2003). Para os autores, as agremiações surgem a partir dos partidos de notáveis ${ }^{5}$ e consistem em uma tentativa de mobilização através da distribuição de favores e/ou de coação. Ao optar por uma organização frágil, centrada nas suas lideranças e dependente de grandes doações e do financiamento público, o PSL também se aproxima do modelo de partidos de quadros.

Alugar um partido também confere ao novo inquilino controle sobre as finanças. Do mesmo modo que em um partido "tradicional", os dirigentes de uma legenda de aluguel distribuem recursos para determinados membros em detrimento de outros.

A maior diferença está na atração de financiadores privados. Um partido de aluguel que permanece nanico enfrenta dificuldades para conseguir um montante razoável de recursos financeiros para suas campanhas. No entanto, uma liderança com lastro social e/ou maior proximidade com setores empresariais pode atrair financiadores para sua campanha, ou seja, o perfil de quem aluga faz diferença na hora de obter recursos financeiros privados.

Entre 2015 e 2019, o PSL foi alugado duas vezes. Primeiro, em 2015, para dissidentes do MBL, o Livres, que almejavam refundar - e renomear - a legenda de acordo com o programa do movimento ${ }^{6}$ (Mayer, 2018). Em 2017, o partido foi alugado para grupos ligados ao até então deputado federal Jair Bolsonaro, com o objetivo de viabilizar sua candidatura à presidência da República em 20187 . A entrada dos grupos bolsonaristas causou a saída do Livres do PSL e sua migração, majoritariamente, para o Partido Novo.

O casamento entre o PSL e o bolsonarismo foi tumultuado devido à tentativa do grupo ligado ao presidente em deter o controle da agremiação e à baixa coesão entre os membros do partido. Devido a inúmeros conflitos e instabilidade, o grupo ligado à família Bolsonaro anunciou no final de 2019 o rompimento com os sociais liberais e a ambição da construção de um novo partido, a Aliança pelo Brasil ${ }^{8}$.

Ao alugar a sua etiqueta para outros grupos ou movimentos, o PSL tornou-se uma espécie de partido incubadora, isso é, é um partido que oferece sua organização para que outros grupos se desenvolvam e, posteriormente, possam tomar o controle da organização para si ou construir um novo partido ${ }^{9}$.

Enquanto incubadora - e partido de aluguel - é fundamental que a ideologia originária seja suficientemente flexível de modo a permitir que os locatários consigam moldar a ideologia partidária de acordo com seus objetivos. É 
${ }^{9}$ A relação entre o PSB e a REDE pode ser encarada como uma relação de incubadora. Em 2014 a REDE não conseguiu regularizar-se a tempo de concorrer nas eleições e, suas lideranças adentraram nos socialistas. Ao fornecer espaço, o PSB atuou como uma espécie de incubadora do movimento, dando-lhe espaço, recursos e, principalmente, tempo para que esses construíssem a sua organização.

10 A nova extrema-direita pode ser dividida em dois grupos. O primeiro trata-se de partidos herdeiros - ou saudosos - dos antigos partidos nazistas e fascistas e ambicionam o retorno desses regimes. $\mathrm{O}$ segundo grupo trata de partidos políticos que defendem valores tradicionais e são contrários às mudanças políticas, sociais e econômicas das últimas décadas (Ignazi, 1992). importante frisar que o aluguel do partido a terceiros consiste em uma estratégia das lideranças partidárias para obtenção de vantagens - políticas e financeiras de modo a favorecer as lideranças dos partidos, seus inquilinos e garantir a sobrevivência da legenda.

Dito isso, quando o bolsonarismo alugou o PSL, este levou o partido para a extrema-direita ${ }^{10} \mathrm{e}$, embora haja indícios que a legenda irá manter o atual programa, existem dúvidas se o partido irá permanecer neste espectro caso ocorra a saída definitiva do grupo do presidente.

Com o bolsonarismo, o PSL se aproximou de temas da nova extremadireita, tais como: a defesa do livre-mercado; críticas ao Estado de bem-estar social - e ao Estado como um todo -; contrários a questões de gênero, raciais, LGBT+, ambientais e de equidade social; além da defesa de valores tradicionais da sociedade. Em suma, a nova extrema-direita rejeita as transformações sociais das últimas décadas e defende políticas neoliberais (Karapin, 1998; Mudde, 2007).

Concluindo, o PSL congregou grupos de extrema-direita que, até então, se encontravam dispersos em vários movimentos sociais, em torno de uma figura populista ${ }^{11}$ que representava a rejeição à política tradicional. A legenda atuou como uma espécie de "hub" ao conectar vários segmentos em uma mesma agremiação. Entretanto, estes grupos não desenvolveram vínculos através do partido, mas sim a partir do novo inquilino, com a legenda restrita apenas a uma ferramenta eleitoral.

Portanto, o PSL serviu como uma espécie de incubadora para que grupos e/ou movimentos sociais da extrema-direita pudessem concorrer nas eleições de 2018 e também gestar seu programa, estratégias e ações de modo a consolidar-se como um importante ator político no cenário brasileiro.

\section{A Análise de Redes Sociais (ARS) e sua aplicação ao financiamento eleitoral do PSL em 2018}

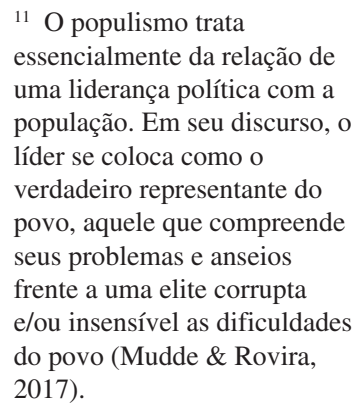

11 O populismo trata essencialmente da relação de uma liderança política com a população. Em seu discurso, o líder se coloca como o verdadeiro representante do povo, aquele que compreende seus problemas e anseios frente a uma elite corrupta e/ou insensível as dificuldades do povo (Mudde \& Rovira, 2017).

Ainda que não tenha ocorrido uma fusão orgânica entre os vários elementos sociais agregados na legenda PSL, o partido obteve um gigantesco êxito no pleito eleitoral de 2018. Dadas as crises e todas as transformações ocorridas no sistema eleitoral brasileiro recente, consideramos o sucesso do PSL emblemático. Sua capacidade de aproveitar a crise enquanto oportunidade para ascender na cena política é de destaque.

O sucesso em um processo eleitoral depende de recursos, que precisam ser captados e distribuídos dentro de uma instituição partidária para seus membros. Como já colocado anteriormente, o fluxo completo de recursos é de difícil captação em um estudo científico, considerando recursos provenientes de atividades ilegais ou que não poderiam ser declarados à justiça eleitoral. Mas ainda assim, os recursos declarados oferecem um mapa, ainda que parcial, do fluxo de recursos utilizados na campanha de 2018.

As eleições de 2018 foram as primeiras nacionais com a adoção do fundo eleitoral e proibição de doações empresariais. Apesar da proibição, as empresas conseguiram "contornar" a regra por meio de doações de pessoas físicas, mesmo que em menor número.

Nessa pesquisa trataremos os dados de receita das campanhas eleitorais de uma forma relacional. Scott (2000) diferencia dados de atributo dos dados relacionais, sendo os primeiros elementos caracterizadores de agentes sociais, e os segundos são informações acerca da relação entre diferentes agentes. Os dados das prestações de contas eleitorais no Brasil podem ser utilizados das duas maneiras. 
${ }^{12}$ Compreendendo estrutura social como um conjunto de relações recorrentes e contínuas, mesmo que dinâmicas. Tal perspectiva relacional de afasta, portanto, das disputas ocorridas na teoria sociológica que trabalham com a dicotomia agência/estrutura. Sobre o debate do pressuposto teórico relacional contido na Análise de Redes Sociais (ARS), conferir Wasserman e Faust (1994) e Scott (2000).

${ }^{13}$ Para isso, analisamos os arquivos de "receitas" dos candidatos, não os arquivos de "doador originário".

\footnotetext{
${ }^{14} \mathrm{O}$ total de transferências financeiras contabilizadas nas prestações de contas foi de 13.524. O número relações financeiras foi inferior ao de transferências porque duas transferências monetárias
}

Não tratamos os dados sobre a perspectiva de atributo. Nesse caso, o valor monetário seria contabilizado e atribuído a determinados agentes, os quais passam a ser classificados de determinada forma (doadores ou receptores) e avaliados pela intensidade da somatória de tais recursos.

Sob uma perspectiva relacional, as transações monetárias são lidas de outra maneira. Também é uma análise quantitativa, porém, as informações caracterizam os contatos entre os agentes e não os agentes em si. Os dados monetários são lidos como criadores de relações e, enquanto conjunto, tais relações são analisadas. Os agentes passam a ser avaliados não apenas pela somatória dos valores recebidos, mas por sua posição nesse conjunto de relações. Além disso, tal perspectiva possibilita a identificação de agrupamentos nesse conjunto. Por isso, Scott afirma que dados relacionais têm o potencial de realizar análises estruturais $^{12}$ da sociedade $(2000$, p. 4), e podem ser mobilizados pela metodologia de Análise de Redes Sociais (ARS).

As prestações de contas dos candidatos e dos órgãos partidários do PSL são fornecidas pelo Tribunal Superior Eleitoral (TSE). Tais dados foram obtidos no "Repositório de dados eleitorais" do site do TSE, em que baixamos os dados dos candidatos e dos órgãos partidários separadamente, que depois foram juntados em tabela única após a filtragem partidária (relações financeiras de agentes vinculados ao PSL). Uma grande limpeza de dados foi necessária na uniformização dos dados, considerando que muitos candidatos ora se identificavam por seu CPF, ora pelo CNPJ de sua campanha. Além de mudanças de grafia nos nomes (tanto dos candidatos como dos doadores). O mecanismo de identificação de repetição do CPF/CNPJ foi usado para identificar diferenças de grafia, e a repetição dos nomes foi usada para identificar erros no CPF/CNPJ.

A prestação de contas permite a geração de dois tipos diferentes de redes de campanha: as redes de receitas e as redes de despesas. Os candidatos prestam contas do volume monetário que recebem e também como gastam esses recursos. Analisamos a primeira rede, a rede de receitas ${ }^{13}$. Elas podem ser classificadas pelo termo técnico da ARS como "rede de adjacência". Ainda que tal rede possua dois gêneros de atores, podendo ser montada como rede de modo- 2 em uma estrutura de dados matricial (Wasserman \& Faust, 1994, p. 29-30), a relação indica mais uma conexão entre atores do que um pertencimento (redes de modo-2 também são chamadas de redes de afiliação), sendo mais recomendável montá-la sob uma matriz quadrática, se esse fosse o caso.

Utilizaremos o software de análise de redes GEPHI 0.9.2. Portanto, nossos dados não foram organizados de maneira matricial, mas sim por listas. Isso significa que temos dois gêneros de atores (source e target), em que determinado "alvo", ou recebedor, pode se tornar "fonte", ou doador, sendo, portanto, uma rede de adjacência.

$\mathrm{Na}$ rede de receitas existem receptores de valores monetários que são exclusivamente candidatos ou órgãos partidários; e doadores, que tanto podem ser pessoas físicas, considerando as novas regras do processo eleitoral vigente em 2018; pessoas jurídicas responsáveis pela coleta de doações coletivas; e os próprios candidatos e órgãos partidários, visto que existe transferência de recursos em que os órgãos partidários distribuem recursos para determinados candidatos que também doam recursos para outros candidatos, além de autodoação. Nessa rede (Figura 1) foi possível observar 7.468 agentes (ou nós) e 8.594 relações financeiras estabelecidas ${ }^{14}$ (ou arestas).

As métricas utilizadas para o estudo dessa rede são de dois gêneros ${ }^{15}$ : análises de centralidade e análises de agrupamento. O primeiro tipo de análise atribui valores aos agentes especificamente. Representam a importância desse agente na rede. Serão duas métricas de centralidade utilizadas em nossa 
entre os mesmos atores e no mesmo sentido foram somadas. Também, no arredondamento dos dados existiam doações com valores abaixo de 50 centavos, e por isso foram excluídas.

15 Existe um terceiro gênero de métrica na metodologia da ARS, as análises de densidade. Essa métrica traz informações sobre a rede como um todo, e é útil na comparação de diferentes redes. Como aqui só trabalharemos com uma rede, esse tipo de análise não será usado.

${ }^{16}$ Esse valor não se trata do total de recursos disponíveis a determinado agente. Como alguns candidatos não só recebem (weighted indegree) como também fazem (weighted outdegree) doações, o valor do "weighted degree" corresponde à somatória desses valores, e não a diminuição de um sobre o outro. Consideramos esse método mais adequado para a aferição da importância de determinado agente na rede.

17 Esse cálculo foi realizado considerando a rede como direcionada.

18 Para mais elementos dos cálculos matemáticos "componente gigante", cf. em especial a equação 12.15 . presentes na filtragem do Newman (2010 p. 396-400),

pesquisa. Primeiro, o weighted degree, ou grau ponderado, que seria a somatória de todas as relações de um agente ponderado pela intensidade do vínculo. Como o vínculo com que estamos trabalhando é o monetário, trata-se da somatória do valor de transações monetárias na qual determinado agente está vinculado ${ }^{16}$. Também utilizaremos o betweenness, ou intermediação, que é um valor numérico atribuído a determinado agente de acordo com o número de geodésicas (caminhos mais curtos entre os nodes) no qual ele faz parte ${ }^{17}$. Os dados de betweenness foram normalizados, ou seja, 1 representa o número máximo possível que o node poderia atingir (estar em todas as geodésicas da rede), e 0 seria o menor valor possível (não estar presente em nenhuma geodésica, no caso do betweenness).

Além das análises sobre a importância de determinados atores, fizemos análises de agrupamento dentro da rede. Iniciaremos com a análise do chamado "componente gigante", que é um filtro hierárquico ${ }^{18}$ que separa a rede em duas. Esse algoritmo identifica um agrupamento principal de agentes interconectados (possuindo algum tipo de conexão direta ou indireta), e retira os "componentes pequenos" isolados, que serão interpretados aqui como agentes marginalizados. Junckes et al. (2019) utilizam esse método de filtragem para analisar a rede de recursos do financiamento de campanha das eleições de 2014 no Brasil.

Depois dessa filtragem inicial, realizamos uma análise de clusterização no componente gigante, capaz de identificar agrupamentos dentro de uma rede completamente conectada. O cálculo que utilizamos foi o de modularidade, muito útil para grandes redes, capaz de estabelecer "estruturas comunitárias hierarquizadas" e trabalhar em redes de arestas com peso (Blondel et al., 2008).

Apresentando alguns dados acerca da rede de receitas das candidaturas e dos órgãos partidários do PSL na eleição de 2018 (Figura 1), encontramos 7468 nós (agentes) e 8.594 arestas (transferências monetárias), em que 1.187 desses agentes são candidatos, 93 são órgãos partidários (considerando o nacional, os estaduais e os municipais) e o restante (6.188 agentes) foram outros doadores.

Ao aplicarmos o primeiro filtro hierárquico, o componente gigante daí derivado da rede de receitas possui 5.244 nós, ou seja, 70,22\% de todos os agentes da rede completa, e 6.404 arestas, ou seja, 74,5\% das relações financeiras (o número delas, não valores monetários). É possível observar que aproximadamente $3 / 4$ da rede de receitas pode ser aglomerada em um componente gigante, enquanto restante estaria em uma posição marginalizada.

\section{IV.I. Os outsiders}

Os outsiders representam quase $1 / 4$ da rede completa, com 196 candidatos e 63 órgãos partidários. Esses órgãos são, em sua maioria, municipais e, apenas 4 são estaduais (Amapá, Goiás, Piauí e Rondônia). Em relação aos estados, é sempre bom relembrar que a legenda foi alugada às pressas, fato que interferiu na formação dos novos diretórios e, consequentemente, na distribuição de recursos. Como estamos trabalhando com um universo total de 1.187 candidatos, percebemos que a rede dos outsiders possui $16,61 \%$ do total de candidatos do PSL. A Figura 2 apresenta os respectivos dados.

Os agentes que estavam fora do "componente gigante" na rede geral de receitas das campanhas de 2014, elaborada na pesquisa de Junckes et al. (2019), representavam $28,9 \%$ dos candidatos, que possuíam apenas $1 \%$ dos recursos das campanhas daquele ano. E apenas 2,3\% deste grupo foram eleitos (Junckes et al., 2019, p.8-9).

Comparando ${ }^{19}$ com os outsiders da rede de todos os partidos em 2014 da pesquisa de Junckes et al. (2019), percebemos que a rede de outsiders do PSL 
Figura 1 - Rede de receitas das campanhas do PSL em 2018

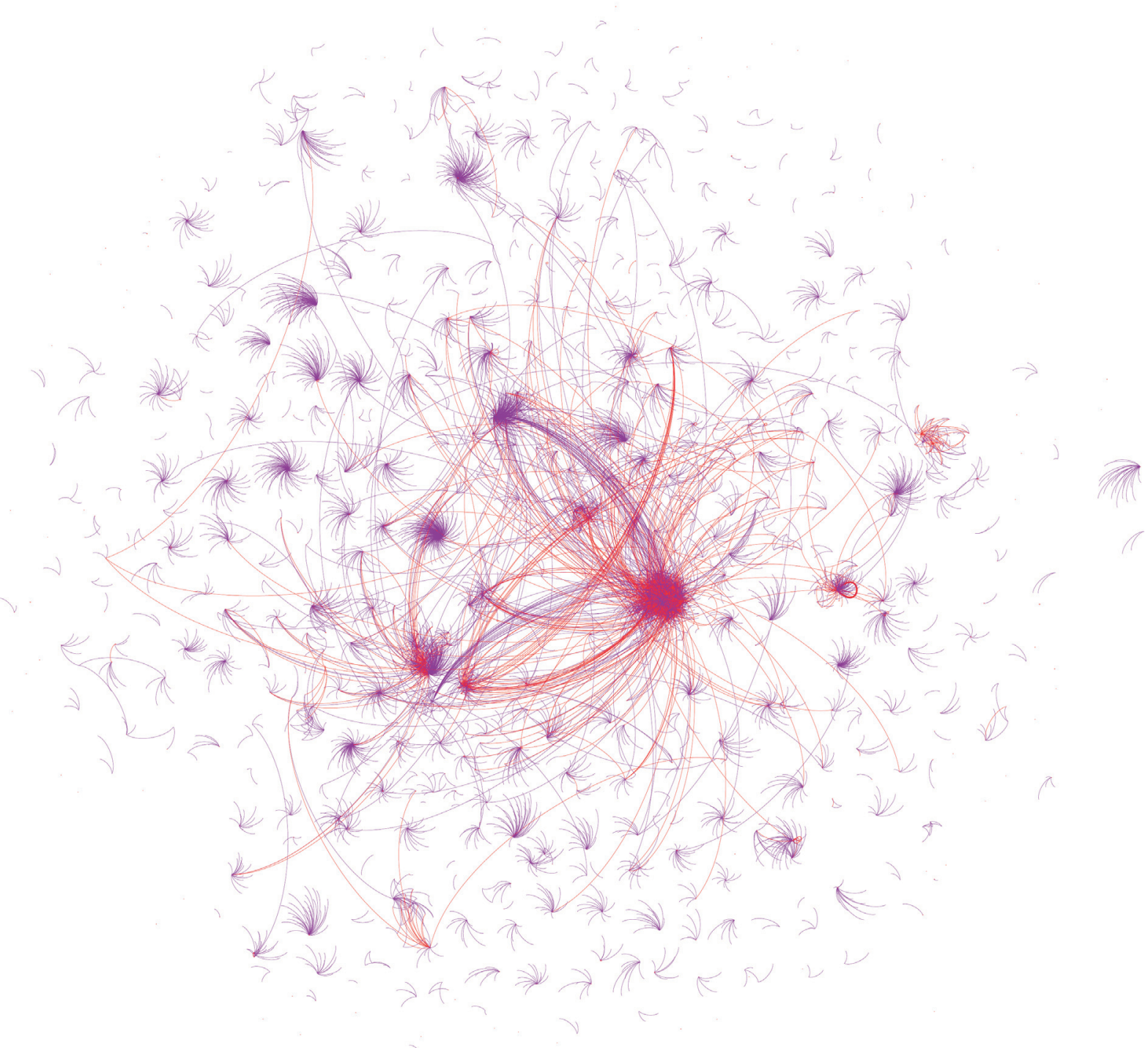

Fonte: Elaboração própria. Dados de prestação de contas da Eleição 2018 disponível no TSE. Distribuição do sociograma organizado pelo algoritmo "OpenOrd”. Cor vermelha para candidatos e órgãos partidários e cor azul para demais doadores. Tamanho definido pela métrica weighted degree. Segundo Cherven (2015), o algoritmo OpenOrd é recomendado para redes grandes, como as que estamos analisando aqui.

19 A "comparabilidade" com a rede da pesquisa de Junckes $e t$ al. (2019) deve ser tomada cuidadosamente. Trata-se de uma base de dados muito semelhante, já que o sistema de prestação de contas produziu tabelas ainda muito semelhantes entre $2014 \mathrm{e}$ 2018. em 2018 possui uma porcentagem menor do total de candidatos $(16,61 \%)$, o que poderia indicar uma maior integração do total de candidatos do partido. Uma possível explicação para esse dado pode encontrar-se na natureza do partido.

Devido a sua natureza de aluguel, o PSL não desenvolveu capilaridade em algumas regiões, fato que dificultou a expansão de sua base. Em outras palavras, a menor porcentagem de candidatos entre os outsiders pode ser explicada pela entrada tardia dos grupos bolsonaristas no final de 2017, o que pode ter dificultado a estratégia de inflar as listas partidárias que a maioria das legendas realizam (fenômeno esse captado na pesquisa de Junckes et al.já que se tratava de uma rede de todos os partidos). 
Figura 2 - Rede do fluxo de receitas das campanhas eleitorais dos candidatos do PSL externos ao "componente gigante"

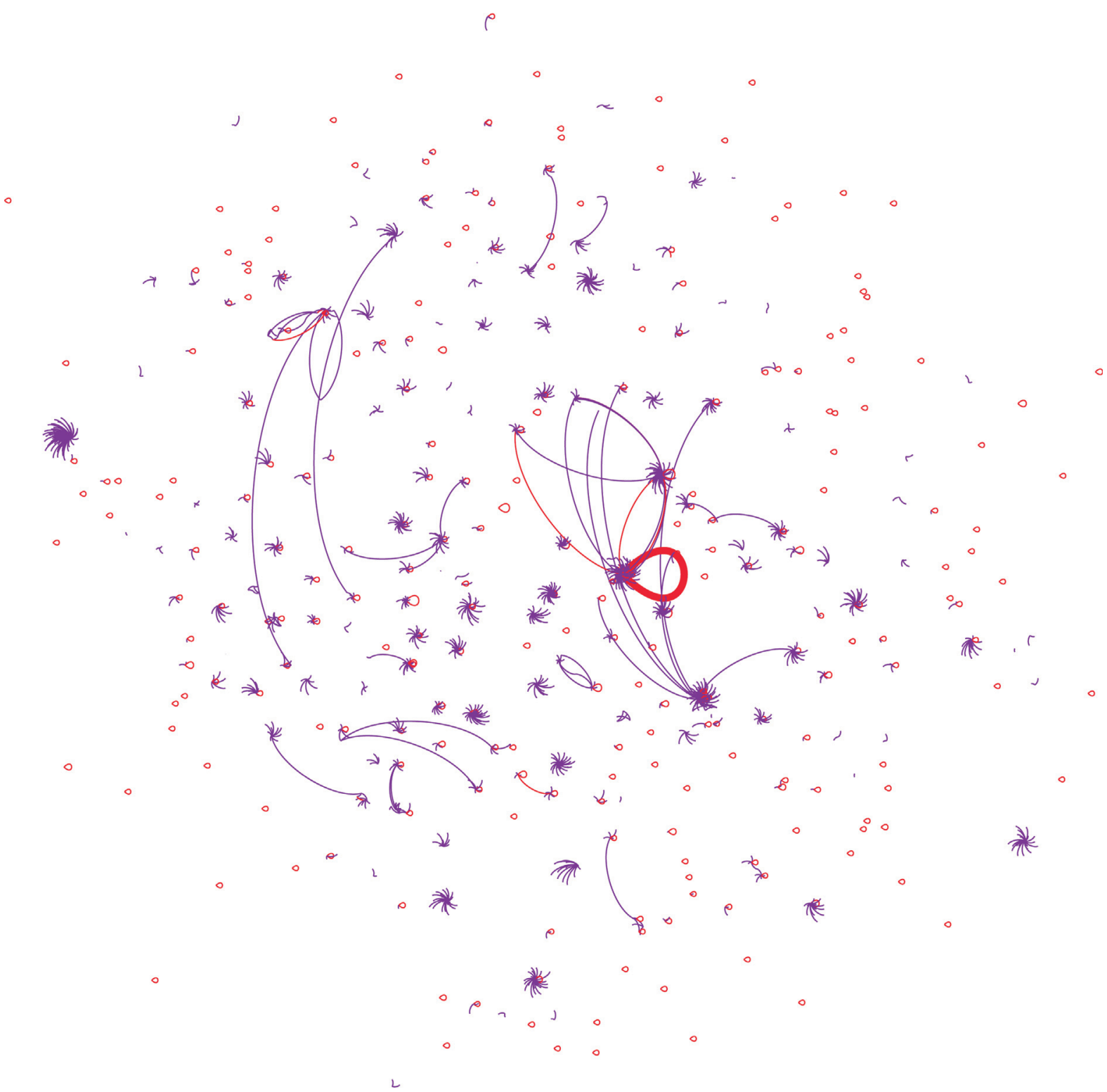

Fonte: Elaboração própria. Dados de prestação de contas da Eleição 2018 disponível no TSE. Distribuição do sociograma organizado pelo algoritmo "OpenOrd". Cor vermelha para candidatos e órgãos partidários e cor azul para demais doadores. Tamanho definido pela métrica weighted degree.

Em relação ao volume de recurso, percebemos que os outsiders do PSL também possuem diferença quando comparados a todos os outsiders da eleição de 2014. Enquanto estes possuíam apenas $1 \%$ dos recursos de campanha naquele ano; em 2018, os outsiders do PSL somaram em suas relações financeiras o total de 11.992 .062 reais. Considerando o total declarado pelos agentes do PSL ao TSE nesse ano (75.142.607 reais), percebemos que os outsiders possuíam 15,95\% de todos os recursos mobilizados, o que indica que a legenda ainda estava em "construção" durante a campanha.

Tratando da capacidade eleitoral dos agentes de tal rede, de um total de 136 candidaturas do PSL eleitas em 2018, 20 delas estavam presentes entre os outsiders. Dentre eles 10 deputados estaduais, 8 deputados federais, a senadora 
20 A senadora Selma Arruda teve o mandato cassado no fim de 2019. eleita pelo Mato Grosso do $\mathrm{Sul}^{20}$ e o governador de Rondônia. O índice de eleitos nessa camada de outsiders é de $14,7 \%$, porcentagem bem mais elevada do que os 2,3\% identificados na pesquisa de Junckes et al. (2019).

A porcentagem mais alta do sucesso eleitoral entre os marginalizados pode ser explicada pela força das questões ideológicas nesse processo eleitoral, além de terem sido mais bem financiados. Em outras palavras, ao contrário dos partidos consolidados (contemplados na pesquisa de Junckes et al.), o PSL não possuía uma forte base de parlamentares que direcionava seus recursos, mas sim era uma junção de diversos grupos ligados a questões de extrema-direita (mesmo que não se auto intitulem como tal) e contrários à política. Por tais características, o partido abriu portas para uma série de novos atores que obtiveram sucesso eleitoral porque eram apoiados por uma ideologia e sem uma dependência organizacional muito intensa.

Candidatos externos ao "componente gigante" normalmente seriam resultado da estratégia, comum a quase todos os partidos brasileiros, de inflar a lista de candidatos de filiados com poucas chances de êxito eleitoral, de modo a auxiliar na superação do quociente eleitoral.

No caso do PSL, a rede indicaria uma menor intensidade da aplicação dessa estratégia, além de uma capacidade eleitoral diferenciada desses tipos de candidatos. O papel da ideologia como recurso político (não dependente do volume monetário transferido) e a baixa capilaridade do partido no país podem ser explicativos do fenômeno de surgimento de candidaturas viáveis entre os outsiders do PSL em 2018.

Assim, os candidatos outsiders no PSL, em comparação aos outsiders de todos os partidos de 2014: i) possuíam número menos elevado, provavelmente pela recente colonização do partido pela extrema-direita e; ii) conseguiram ter maior eficácia eleitoral, sobretudo pelo descrédito da política tradicional e o crescimento da figura de Bolsonaro.

Variáveis como impedimento de financiamento por pessoa jurídica, o baixo montante monetário oficial mobilizado pelo partido, o papel ideológico exercido pro Bolsonaro - e o potencial eleitoral deste à margem da força monetária - e a rejeição de grande parte da população aos partidos tradicionais podem explicar a diferença do papel dos outsiders do PSL em 2018, quando comparados com os outsiders de 2014 (e talvez com outros outsiders em 2018, o que poderia ser testado com uma pesquisa semelhante a de Junckes et al. para tal processo eleitoral).

Os outsiders no PSL, portanto, possuem um papel relevante no processo eleitoral de 2018. Mesmo que não estejam diretamente conectados com os fluxos monetários de receita do "componente gigante", tiveram uma posição material significativa e um resultado eleitoral satisfatório.

IV.II. O componente gigante: a rede interconectada de fluxos financeiros do financiamento de campanha do PSL em 2018

O componente gigante da rede de receitas, representando da rede completa, revela uma teia intricada de fluxos financeiros entre a maior parte dos candidatos do PSL em 2018. Por mais que estar nela não seja uma necessidade para a obtenção de recursos ou para o sucesso eleitoral, ainda assim significa estar conectado financeiramente com diversas campanhas. Dentre elas a que obteve a presidência da república.

Dado o grande tamanho desse componente, seria útil decompô-lo em mais unidades a fim de desenvolver a análise. Para este fim, as análises de clusteri$z a c ̧ a ̃ o$ se mostram úteis, pois são capazes de identificar agrupamentos na rede. $\mathrm{O}$ 
cálculo que utilizamos foi o de modularidade, mencionado anteriormente no artigo. Através desse cálculo foram identificadas 97 comunidades na rede, sendo que apenas as 4 maiores possuíam mais do que 5\% do total de agentes do componente gigante. A Figura 3 indicará os 4 maiores agrupamentos através de cores.

Tratando da maior comunidade, a vermelha, percebe-se que o algoritmo "OpenOrd" o dispersou em vários centros, dois deles mais significativos do que os outros. Neste cluster havia 30 candidatos, apenas a deputado (Estadual e Federal). E destes, 16 deles foram eleitos (mais de 50\% deles).

Mesmo sendo um partido de aluguel e composto por uma série de "novatos", o partido também apresenta alguns comportamentos que se assemelham aos dos partidos tradicionais (ou consolidados), como direcionar recursos para determinadas candidaturas ao invés de uma distribuição mais igualitária entre

Figura 3 - O componente gigante da rede de receitas das campanhas do PSL em 2018

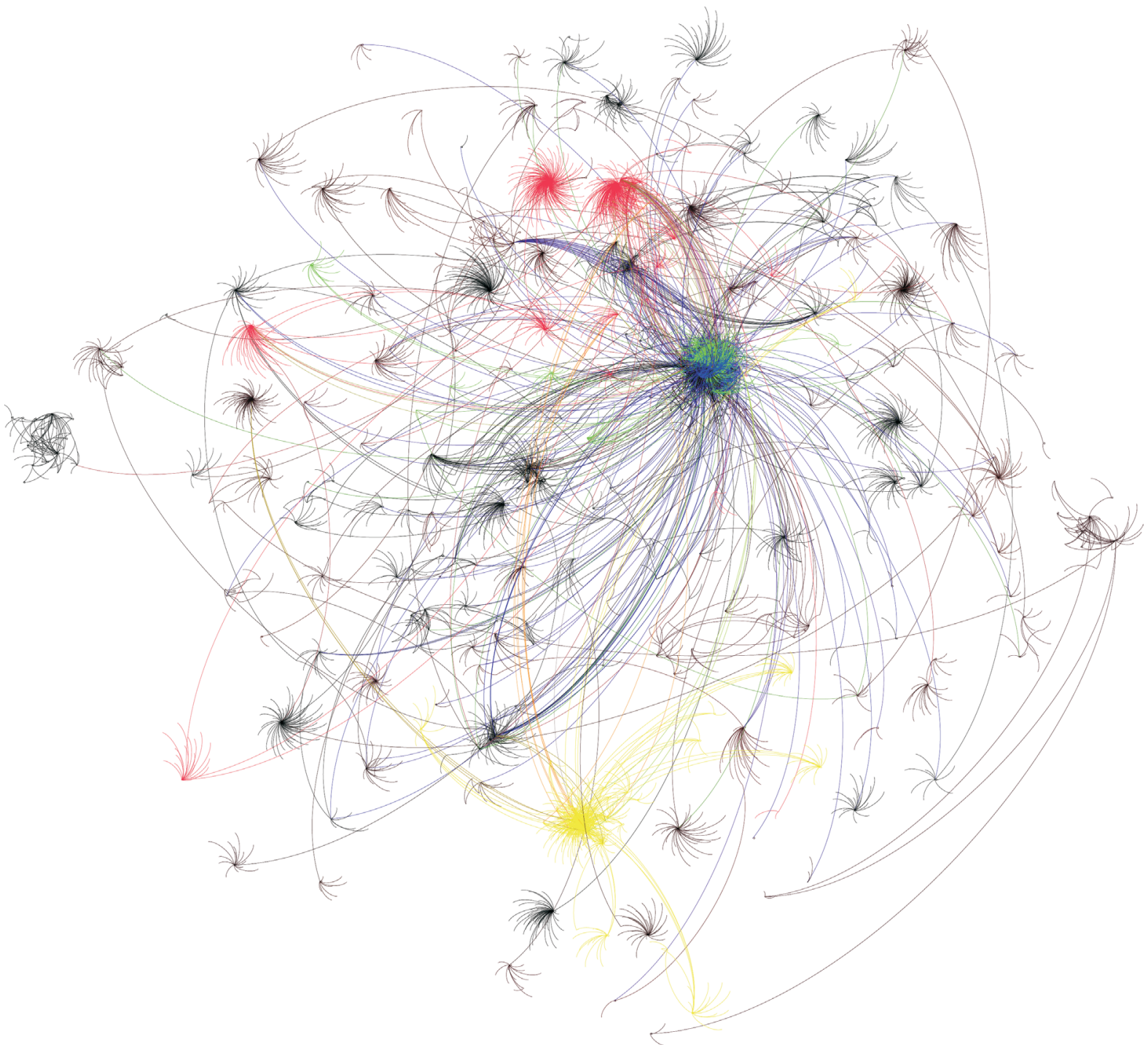

Fonte: Elaboração própria. Dados de prestação de contas da Eleição 2018 disponível no TSE. Distribuição organizada pelo algoritmo "OpenOrd". Cor vermelha para a maior comunidade $(15,26 \%$ de todos os nodes), cor azul para a segunda maior comunidade $(11,25 \%)$, cor amarela para a terceira maior $(7,67 \%)$ e verde para a quarta maior $(6,79 \%)$. O restante das comunidades permaneceu com a cor preta. A cor das arestas é da mesma cor do node que está efetuando a doação. O tamanho dos nodes é definido por weighted degree. 
os candidatos. Segundo Cervi (2010), os partidos buscam privilegiar candidaturas que possuem maior potencial eleitoral que outras. No caso do PSL, existe a insegurança do resultado devido à quantidade de candidatos que concorreram pela primeira vez. Todavia, a legenda agregou alguns nomes com grande presença nas redes sociais e protagonismo em movimentos conservadores, o que levou o partido a investir em certos nomes ao invés de outros. A Tabela 1 dispõe dos dados de centralidade do cluster vermelho.

A Tabela 1 mostra o maior fornecedor de recursos do cluster. É a empresa chamada "Vaquinha.com", responsável por operar financiamentos coletivos através da internet. A centralidade da utilização da empresa de financiamento coletivo decorre de mudanças na legislação eleitoral em 2017 que passou a permitir este tipo de financiamento. Devido a sua proximidade com movimentos sociais, como o Vem pra rua, e/ou sua grande presença na internet, seus membros conseguiram capitalizar politicamente a sua influência na internet. Outro elemento que a tabela nos mostra, especificamente em relação ao betweenness, é que existe uma dispersão geográfica dos principais agentes deste cluster, o que poderia explicar sua fragmentação no algoritmo "OpenOrd", considerando que agentes em estados diferentes, mesmo que reunidos por um método de coleta de dinheiro próximo, ainda assim estabelecem outros tipos de relações de coleta de dinheiro mais variados.

Tratando agora da comunidade azul, observamos nesta um número muito mais significativo de candidatos, 248 pessoas. Em sua grande maioria composta por deputados (estaduais e federais), possuindo dois candidatos ao senado e um a governador, nenhum destes três sendo eleito. O sucesso eleitoral de tal cluster também foi muito inferior, com apenas 14 eleitos $(5,64 \%$ dos candidatos obtiveram sucesso eleitoral).

Quais fatores explicam o insucesso eleitoral deste cluster? O PSL apostou muito em candidatos que se encontravam fora da arena parlamentar e no forte discurso anti-político, em um momento em que este sentimento estava fortemente enraizado na sociedade. Esse seria o cluster mais "institucional" do PSL, possivelmente sendo menos beneficiado desse recurso ideológico. Outro elemento é o fato de nesse cluster estarem congregados vários órgãos partidários que, naturalmente, se conectam com diversos candidatos, mesmo que estes não tenham grande viabilidade eleitoral.

Portanto, mesmo com essa porcentagem de sucesso inferior, o cluster azul possuiu agentes de destaque dentro do PSL.

A Tabela 2 demonstra que o cluster azul, também, possui uma grande dispersão geográfica, embora ele permaneça bem concentrado dentro do socio-

Tabela 1 - Índices de centralidade dos principais nós do cluster vermelho

\begin{tabular}{lccccc}
\hline Node & Estado & Weighted degree & Node & Estado & Betweenness \\
\hline Carla Zambelli Salgado & SP & 517611 & Luciano LorenziniZucco & RS & 0.000004 \\
vakinha.com & & 375858 & $\begin{array}{c}\text { Carlos Roberto Coelho de } \\
\text { Mattos Junior }\end{array}$ & RJ & 0.000004 \\
Luciano LorenziniZucco & RS & 263469 & Elieser Girao Monteiro Filho & RN & 0.000003 \\
$\begin{array}{l}\text { Luiz Philippe de Orleans } \\
\text { e Braganca }\end{array}$ & SP & 258625 & Caroline Rodrigues de Toni & SC & 0.000001 \\
$\begin{array}{l}\text { Marcus Vinicius de } \\
\text { Araujo Dantas }\end{array}$ & SP & 203312 & Marcio Gualberto dos Santos & RJ & 0.000001 \\
\hline
\end{tabular}

Fonte: Elaboração dos autores com base nos dados extraídos da rede de receita das campanhas do PSL de 2018, através do programa Gephi. 
Tabela 2 - Índices de centralidade dos principais nós do cluster azul

\begin{tabular}{lccccc}
\hline Node & Estado & Weighted degree & Node & Estado & Betweenness \\
\hline PSL nacional & & 32155638 & PSL nacional & 0.001186 \\
Luciano Caldas Bivar & PE & 2214688 & PSL estadual/distrital RJ & RJ & 0.000246 \\
PSL estadual/distrital PE & PE & 1597046 & PSL estadual/distrital BA & BA & 0.000189 \\
PSL estadual/distrital RJ & RJ & 1238774 & Flavio AntonioMoreno da Silva & AL & 0.000058 \\
PSL estadual/distrital PB & PB & 1196085 & PSL estadual/distrital AM & AM & 0.000053 \\
\hline
\end{tabular}

Fonte: Elaboração dos autores com base nos dados extraídos da rede de receita das campanhas do PSL de 2018, através do programa Gephi.

grama. É de destaque o peso dos órgãos partidários nele e do próprio presidente - e "dono" - do partido, Luciano Caldas Bivar.

Entre os órgãos, a centralidade de Pernambuco na rede vem do acordo de cessão do partido para a família Bolsonaro, em que Bivar cede a legenda em troca de recursos e manutenção do controle da agremiação em seu estado e, posteriormente, retorno a presidência nacional do partido. A coordenação da campanha eleitoral de Bolsonaro no Nordeste fica sob a tutela do, até então, candidato a deputado federal Julian Lemos do PSL paraibano, fato que explica o repasse de recursos para o Estado. Por fim, a forte presença no Rio de Janeiro ocorre pelo estado ser reduto eleitoral da família do presidente da República.

Excetuando o Rio de Janeiro, onde a legenda obteve um dos seus melhores desempenhos eleitorais de 2018, o restante do cluster azul não se traduz em votos, com Pernambuco e Paraíba elegendo apenas um parlamentar cada.

No cluster amarelo, cujos dados constam na Tabela 3, tivemos uma quantidade razoável de candidatos (52 pessoas), também em sua maioria Deputados, com um candidato a senador e um a governador. Mas nesse caso, o governador foi eleito. É Carlos Moisés, governador do Estado de Santa Catarina. A eficácia eleitoral de tal cluster foi de 8 candidaturas eleitas, ou seja, 15,38\% do total. Apresentamos alguns dados deste cluster:

É possível verificar que o cluster amarelo possui um regionalismo forte. Nela, todos os candidatos foram de Santa Catarina, mostrando que os catarinenses do PSL formaram uma conexão própria para a obtenção de receitas durante a campanha, e que pôde ser identificada através do cálculo de modularidade. A coesão interna do agrupamento catarinense do PSL poderá ter algum peso explicativo sobre a relação que o governo deste estado teve com a presidência da República em 2019.

A Tabela 4 indica os dados do cluster verde, que é o menor dos quatro principais, mas possuiu uma quantidade significativa de candidatos. Foram 70

Tabela 3 - Índices de centralidade dos principais nós do cluster amarelo

\begin{tabular}{lccccc}
\hline Node & Estado & Weighted degree & Node & Estado & Betweenness \\
\hline Carlos Moises da Silva & SC & 956807 & Carlos Moises da Silva & SC & 0.000338 \\
Lucas de Souza Esmeraldino & SC & 312356 & Lucas de Souza Esmeraldino & SC & 0.000051 \\
Lucas de Souza Esmeraldinho & & 183285 & PSL estadual/distrital SC & SC & 0.000051 \\
Rodrigo da Silva Turatti & SC & 181956 & Jeferson Lopes & SC & 0.000007 \\
Jose Antonio Martins & & 100000 & Lucas de Souza Esmeraldinho & 0 \\
\hline
\end{tabular}

Fonte: Elaboração dos autores com base nos dados extraídos da rede de receita das campanhas do PSL de 2018, através do programa Gephi. 
Tabela 4 - Índices de centralidade dos principais nós do cluster verde

\begin{tabular}{lccccc}
\hline Node & $\begin{array}{c}\text { Estado de } \\
\text { candidatura }\end{array}$ & $\begin{array}{c}\text { Weighted } \\
\text { degree }\end{array}$ & Node & $\begin{array}{c}\text { Estado de } \\
\text { candidatura }\end{array}$ & Betweenness \\
\hline PSL estadual/distrital SP & & 2338407 & PSL estadual/distrital SP & & 0.000156 \\
Paulo Sergio Abou Anni & SP & 772555 & Paulo Sergio Abou Anni & SP & 0 \\
Alexandre Said Bussab & SP & 651989 & Alexandre Said Bussab & SP & 0 \\
Sergio Olimpio Gomes & SP & 380324 & Sergio Olimpio Gomes & SP & 0 \\
Vitor Hugo Riccomini & SP & 277881 & Vitor Hugo Riccomini & SP & 0 \\
\hline
\end{tabular}

Fonte: Elaboração dos autores com base nos dados extraídos da rede de receita das campanhas do PSL de 2018, através do programa Gephi.

deputados (federais e estaduais) e um senador eleito, Major Olímpio. Nesse cluster é possível identificar 11 indivíduos eleitos (7 deputados estaduais, 2 deputados federais e o senador), o que nos traz um índice de $15,71 \%$ de pessoas eleitas. Da mesma maneira que o cluster acima, o verde também apresenta um forte regionalismo. Apenas 6 de todos os 70 candidatos estavam fora do estado de São Paulo, e todos os eleitos possuíam suas candidaturas nesse Estado.

Os agentes do cluster verde possuem valor zero em betweenness, com exceção do órgão partidário do PSL de São Paulo, o que mostra que os agentes desse cluster não possuem um papel grande de intermediação na rede como um todo. E o primeiro lugar do órgão partidário do Estado nas duas métricas de centralidade mostra a importância da estrutura partidária na organização do PSL paulista, o que não seria o caso dos catarinenses.

A Tabela 5 apresenta uma comparação de alguns dados dos quatro clusters principais identificados no componente gigante.

Primeiramente, destacamos o valor mais elevado do betweenness do maior agente de intermediação do cluster azul, se comparado com os demais. Se o leitor retornar aos índices de betweenness das tabelas individuais dos clusters também vai perceber que esse índice é mais elevado entre os agentes da

Tabela 5 - Comparação entre os diferentes componentes da rede

\begin{tabular}{|c|c|c|c|c|}
\hline & Vermelho & Azul & Amarelo & Verde \\
\hline Número de nodes & $800(15,26 \%)$ & $590(11,25 \%)$ & $402(7,67 \%)$ & $357(6,79 \%)$ \\
\hline Número de candidatos & 30 & 248 & 52 & 71 \\
\hline $\begin{array}{l}\text { Porcentagem de candidatos } \\
\text { eleitos }\end{array}$ & $\begin{array}{c}53,33 \% \\
\text { (16 indivíduos) }\end{array}$ & $\begin{array}{c}5,64 \% \\
\text { (14 indivíduos) }\end{array}$ & $\begin{array}{c}15,38 \% \\
\text { (8 indivíduos) }\end{array}$ & $\begin{array}{c}15,71 \% \\
\text { (11 indivíduos) }\end{array}$ \\
\hline $\begin{array}{l}\text { Porcentagem de candidatos } \\
\text { do Estado mais frequente }\end{array}$ & $\begin{array}{l}30 \% \text { de candidatos } \\
\text { por São Paulo }\end{array}$ & $\begin{array}{l}25 \% \text { de candidatos } \\
\text { pelo Rio de Janeiro }\end{array}$ & $\begin{array}{c}100 \% \text { de candidatos } \\
\text { por Santa Catarina }\end{array}$ & $\begin{array}{c}91,54 \% \text { de candidatos } \\
\text { por São Paulo }\end{array}$ \\
\hline $\begin{array}{l}\text { Somatória do weighted } \\
\text { indegree }^{\mathrm{I}} \text { de todos }\end{array}$ & 2.057.276 & 23.031 .642 & 2.064 .802 & 3.976 .356 \\
\hline $\begin{array}{l}\text { Somatória do weightedout } \\
\text { degree de todos }\end{array}$ & 2.080 .073 & 25.462 .235 & 2.076 .427 & 3.517 .747 \\
\hline Betweenness mais elevado & 0.000004 & 0.001186 & 0.000338 & 0.000156 \\
\hline
\end{tabular}

Fonte: Elaboração dos autores com base nos dados extraídos da rede de receita das campanhas do PSL de 2018, através do programa Gephi.

IA métrica weighted indegree corresponde a todo o valor recebido por um node na rede. A métrica weighted outdegree corresponde a todo valor doado por um node. No caso da análise individual utilizamos a métrica que somava os dois. Agora, como estamos tratando de clusters, convém separar tais dados. Estes são valores doados e recebidos tanto por candidatos como por órgãos partidários. 
comunidade azul do que nas demais. Isso mostra que a comunidade azul tem um papel geral de intermediação dentro do componente gigante. Nesse componente, 3 dos cinco maiores betweenness do componente gigante pertencem a agentes do cluster azul.

Os clusters amarelo e verde possuem agentes com grande capacidade de intermediação, respectivamente Carlos Moises (com o terceiro maior betweenness do componente gigante) e o PSL Estadual/Distrital SP (com o oitavo maior betweenness). O cluster amarelo possui outros agentes com essa capacidade de intermediação, porém em nível menos elevado que o cluster azul. Mas no cluster verde, o único agente que possui tal papel é o órgão partidário, o que denota um papel institucional partidário mais elevado no Estado de São Paulo do que no Estado de Santa Catarina.

Porém, capacidade de intermediação dentro da rede de receitas das campanhas eleitorais não se mostra de grande eficácia para ser eleito. Isso pode ser sustentado observando a comunidade vermelha. Mesmo possuindo um baixo grau de intermediação, tal comunidade possuiu um índice bastante significativo de sucesso eleitoral. Trata-se de uma comunidade muito ampla com um baixo número de candidatos, com apenas um órgão partidário municipal (de Uruguaiana), e com um número muito grande de doadores (e que se destaque o papel da instituição "Vakinha.com", empresa de financiamento coletivo).

Como podemos observar pelas métricas de weighted indegree weighted outdegree, esse sucesso eleitoral não pode ser explicado pelo volume monetário obtido por tal comunidade. A quantidade de dinheiro estava concentrada na comunidade azul, da qual pertenciam os principais nodes conectados com a estrutura partidária. Mas mesmo com uma quantidade menos elevada de dinheiro, um grande número de doadores permitiu uma maior eficácia eleitoral à comunidade vermelha. O que poderia indicar que, no processo de transformação da legislação eleitoral brasileira, com o impedimento de financiamento de pessoas jurídicas, o engajamento de um número grande de pessoas para doações eleitorais (mesmo que de valor monetário reduzido) pode trazer resultados eleitorais positivos.

Até então fizemos a análise das maiores comunidades presentes no componente gigante da rede de receitas das campanhas eleitorais do PSL no ano de 2018, as que possuíam maior número de agentes (nodes) incluso. Mas existe uma ausência gritante em nossa análise até o momento: a campanha presidencial está localizada onde na rede?

Jair Bolsonaro está localizado em um agrupamento que ocupa o oitavo lugar em termos de tamanho (número de nodes), com apenas 2,8\% dos nodes do componente gigante (148 nodes ao total). Nesse cluster havia 14 candidatos, dentre eles sua candidatura a presidente e um senador (seu filho, Flávio Bolsonaro). Eduardo Bolsonaro, então candidato a deputado federal, também está presente nesse cluster, não havendo nenhum outro candidato do mesmo sobrenome entre eles.

A taxa de sucesso eleitoral de tal comunidade é de 50\%, com 7 candidatos eleitos. O que é uma taxa muito significativa, comparando com as outras comunidades acima tratadas. Continuando com esta comparação, suas taxas de weighted indegree (quanto os agentes dessa comunidade receberam) e weighted outdegree (quanto os agentes dessa comunidade doaram) foram, respectivamente, 6.046 .690 e 5.522.580 reais. A inferioridade do segundo valor denota que este cluster recebeu recursos externos de outras comunidades, o que é esperado considerando a candidatura presidencial. Porém, possuir nodes que ao todo doaram mais de 5 milhões (considerando o número inferior de nodes que tal comunidade possui) indica uma capacidade financeira própria de tal cluster. 
A superioridade desses valores quando comparados com as comunidades vermelha, amarela e verde também pode ser explicada pela variável presidencial. E sua inferioridade em relação ao cluster azul pode ser explicado pela grande quantidade de órgãos partidários pertencentes à esta comunidade, assim como o grande número de candidatos presentes ali.

Mesmo sendo uma comunidade de tamanho reduzido, o cluster de Bolsonaro possui agentes com grande valor monetário e também com alto betweenness. Jair Bolsonaro possui o segundo maior betweenness do componente gigante (0.000999), e Flávio Bolsonaro possui o sétimo (0.000157).

Entre os doadores, a comunidade de Bolsonaro possui a "AIXMOBIL Serviços e Participações ltda”, empresa de pagamentos que deve ter operado o sistema de coleta de doações de campanha (o que o assemelha à comunidade vermelha, que possuía a empresa "Vakinha.com").

Portanto, Bolsonaro pertencer à comunidade que, em termos de tamanho, está em posição reduzida, não significa que sua importância ou a importância da sua comunidade seja diminuta. $\mathrm{O}$ grande volume monetário, o alto índice de betweenness e seu sucesso eleitoral mostram a importância da oitava comunidade do componente gigante.

Mas o fato do candidato à presidência da república formar um cluster próprio, e não estar integrado ao menos ao cluster dos principais órgãos partidários (o azul) é algo que se mostra contra intuitivo. Pesquisas futuras que repliquem o mesmo método aqui aplicado sobre outros partidos em 2018 poderiam nos mostrar, primeiro, se o número de 97 comunidades que se formaram no componente gigante do PSL denotaria uma fragmentação do partido. E estudos que foquem outras candidaturas presidenciais poderiam nos mostrar se o não pertencimento do candidato à presidência no maior cluster (seja em termos de número de nodes, o vermelho, seja em valor monetário, o azul) seria fenômeno específico do PSL.

Mas o que tal dado pode nos dizer acerca da realidade política atual é de que existiu uma separação entre os órgãos partidários do PSL e a candidatura presidencial nas eleições de 2018, o que pode ser uma variável explicativa dos atritos que ocorreram entre o presidente e o PSL a partir de 2019, e a própria tentativa, até então ineficaz, de fundação do novo partido. Talvez, o cálculo político da família Bolsonaro é de que possuem uma independência em relação ao PSL em termos de formação de uma rede para o financiamento futuro de campanha.

\section{Considerações Finais}

São dois tipos de considerações que podemos explorar ao final do presente artigo. Primeiro, considerações acerca da mobilização da metodologia que aplicamos em mais pesquisas de financiamento eleitoral. E segundo, como o resultado empírico de nossa pesquisa ajuda na caracterização do PSL.

Iniciemos pela possível replicação do método em futuras pesquisas de financiamento de campanha. Este é um elemento importante, pois a comparação da rede aqui analisada com redes de outros partidos permitiria a análise de determinados dados quantitativos de maneira muito mais assertiva.

Uma avaliação precisa dos outsiders do PSL dependeria da comparação com os outsiders dos outros partidos. Para avaliarmos a "normalidade" ou "excepcionalidade" deles, deveríamos comparar os recursos e o resultado eleitoral dos outsiders de outros partidos individualmente. Uma pesquisa desse gênero, utilizando as métricas de Análise de Redes Sociais, poderia também fazer 
análises de densidade das redes dos outsiders, para verificar se estes no PSL estavam mais coesos ou não do que os outsiders de outros partidos.

Além dos outsiders, uma comparação importante a ser feita é com o "componente gigante" dos outros partidos que também lançaram candidaturas à presidência. Qual o posicionamento da candidatura presidencial dos outros partidos na rede de receitas de campanhas do partido como um todo? Existem isolamentos da mesma forma que no PSL? Ou esse caso foi excepcional? E se não houve isolamento, quais as características do agrupamento congregado na candidatura presidencial nos outros partidos?

A Análise de Redes Sociais, quando mobilizada de maneira comparada, oferece uma grande potencialidade. Mas ainda que tais pesquisas estejam em um horizonte, os resultados presentes já oferecem indicadores que permitem caracterizar que o PSL não criou a extrema-direita brasileira, mas serviu de receptáculo para ela.

Consideramos plausível, a partir da análise bibliográfica e das informações eleitorais, sustentar que ao alugar a legenda, os sociais liberais receberam novos membros, recursos, e obtiveram grande sucesso eleitoral nas eleições de 2018. A onda conservadora representada pelo bolsonarismo alçou o PSL de nanico - e irrelevante - a uma das principais forças políticas do país.

A rede de receita das campanhas vinculadas ao PSL nas eleições de 2018 também permite afirmar que o aluguel do partido não foi para apenas para um político com o objetivo de viabilizar uma campanha (presidência), mas para um nome que conseguiu aglutinar diversos setores conservadores e extremistas ao seu redor, mesmo sem uma base pré-existente.

Os componentes presentes entre os outsiders apresentaram grande diversidade, com apostas em candidatos novatos. A alta presença de candidatos nestes componentes, recursos monetários significativos, e o sucesso eleitoral entre esses, evidencia o caráter de movimento - ou onda - do partido, que soube se aproveitar da crise dos partidos políticos tradicionais.

Além disso, o "componente gigante" da rede permite traçar comentários acerca do papel do dinheiro nas campanhas do partido. Segundo a bibliografia especializada, existe uma forte relação entre quantidade de recursos financeiros e sucesso eleitoral. No caso do PSL, a união de segmentos extremistas e antipolíticos fez com que a legenda apresentasse um padrão diferente do previamente descrito pela literatura especializada. Ou seja, os recursos financeiros são importantes, mas foi observado um reduzido sucesso eleitoral no cluster com maior montante financeiro.

Por fim, a separação da candidatura presidencial do cluster mais institucional da rede é elemento de destaque, considerando a própria saída de Jair Bolsonaro do partido no final de 2019. Complementando tal aspecto da rede com as acusações de Caixa 2 (Folha de São Paulo, 2019) e de burlar as regras de financiamento empresarial, principalmente na contratação de empresas de disparos em massa de mensagens de Whatsapp, seria possível inferir uma certa "independência" financeira da figura presidencial em relação ao partido. Mostrando que a "gestação" do bolsonarismo realizada pelo PSL não se referiria à constituição de meios de obtenção de receita para a realização de campanha, mas sim o oferecimento dos requisitos partidários exigidos pelo sistema eleitoral brasileiro para possibilitar o lançamento da candidatura. 
Rodolfo Palazzo Dias (rodolfo.dias@ gmail.com) é doutor em Sociologia Política pela UFSC, mestre em Ciência Política pela UNICAMP, bacharel e licenciado em Ciências Sociais pela UFPR e bacharel em Relações Internacionais pela UNICURITIBA. Atualmente é pós-doutorando no Programa de pós-graduação em Sociologia e Antropologia (PPGSA/UFRJ).

Rodrigo Mayer (mayer.rrm@gmail.com)é bacharel e licenciado em Ciências Sociais pela UFPR, mestre em Ciência Política pela UFPR, é doutor em Ciência Política pela UFRGS e possui estágio pós-doutoral em Sociologia Política na UFSC. Atualmente é professor de Sociologia no Departamento de Educação da UEPG.

\section{Referências}

Blondel, V., Guillaume, J., Lambiotte, V. \& Lefebvre, E. (2008) Fast Unfolding of Communities in Large Networks. Journal of Statistical Mechanics: Theory and Experiment, 10(s/n), pp.1-12. DOI: 10.1088/1742-5468/2008/10/P10008

Carazza, B. (2018) Dinheiro, eleições e poder: as engrenagens do sistema político brasileiro. São Paulo: Companhia das Letras.

Cervi, E. (2010) Financiamento de campanhas e desempenho eleitoral no Brasil: análise das contribuições físicas, jurídicas e partidos políticos nas eleições de 2008 nas capitais de Estado. Revista Brasileira de Ciência Política, s/v(4), pp.135-167.

Cherven, K. (2015) Mastering gephi network visualization: produce advanced network graphs in Gephi and gain valuable insights into your network datasets. Birmingham: PACKT Publishing.

Claessens, S., Feijen, E. \&Laeven, L. (2008) Political connections and preferential Access to finance: the role of campaign contributions. Journal of Financial Economics, 88(3), pp.554-580. DOI: 10.1016/j.jfineco.2006.11.003

Duverger, M. (1970) Partidos políticos. Rio de Janeiro: Zahar/UNB.

Gunther, R. \& Diamond, L. (2003) Species of political parties: A new tipology. Party Politics, 9(2), pp.167-199. DOI: $10.1177 / 13540688030092003$

Horochovski, R., Junckes, I., Silva, E., Silva, J. \& Camargo, N. (2016) Estruturas de poder nas redes de financiamento político nas eleições de 2010 no Brasil. Opinião Pública, 22(1), pp.28-55. DOI: 10.1590/1807-0191201622128

Ignazi, P. (1992) The Silent Counter-Revolution: Hypotheses on the Emergence of Extreme Right-Wing Parties in Europe. European Journal of Political Research, 22(1), pp.3-34. DOI: 10.1111/j.1475-6765.1992.tb00303.x

Junckes, I., Horochovski, R., Camargo, N., Silva, E. \& Chimin, A. (2019) Poder e Democracia: Uma análise da rede de financiamento eleitoral em 2014 no Brasil. Revista Brasileira de Ciências Sociais, 34(100), pp.1-22. DOI: $10.1590 / 3410006 / 2019$

Karapin, R. (1998) Radical-right parties and neo-fascist political parties in Western Europe. Comparative Politics, 30(2), pp.213-234. DOI: $10.2307 / 422288$

Kestler, T., Krause, S. \& Lucca, J. B. (2013) Los Break-in parties en América Latina: ¿éxito o fracaso? Revista Debates, 7(2), pp.159-171. DOI: $10.22456 / 1982-5269.42030$

Mancuso, W. (2012) Empresas e financiamento de campanhas eleitorais de candidatos a deputado federal pelo estado de São Paulo, nas eleições de 2002 e 2006. In: A. Dalla Costa, W. Iglecias, D. Gros, M. Etcheverry \& J. Mick, (orgs). Desenvolvimento e crise na América Latina: estado, empresas e sociedade. Curitiba: CRV, pp.139-178.

Mancuso, W. (2015) Investimento eleitoral no Brasil: balanço da literatura (2001-2012) e agenda de pesquisa. Revista de Sociologia e Política, 23(54), pp.155-183. DOI: 10.1590/1678-987315235409

Mancuso, W., Horochovski, R. \& Camargo, N. (2018) Financiamento eleitoral empresarial direto e indireto nas eleições nacionais de 2014. Revista Brasileira de Ciência Política, s/v(27), pp.9-36. DOI: 10.1590/0103-335220182701

Mancuso, W., Horochovski, R., Junckes, I. \& Camargo, N. (2021) Pragmatism or ideology? Business sectors and campaign financing in 2014. E-Legis - Revista Eletrônica do Programa de Pós-Graduação da Câmara dos Deputados, 14(34), pp.29-49.

Mancuso, W. \& Speck, B. (2014) Financiamento de campanhas e prestação de contas. Cadernos Adenauer, 15(1), pp.135-150.

Mayer, R. (2018) Partidos políticos no Brasil: do Império à Nova República. Curitiba: Editora InterSaberes.

McMenamin, I. (2012) If money talks, what does it say? Varieties of capitalism and business financing of political parties. World Politics, 16(1), pp.1-38. DOI: 10.1017/S004388711100027X

McMenamin, I. (2013) If money talks, what does it say? Corruption and business financing of political parties. Oxford: Oxford University Press.

McMenamin, I. (2019) Party identification, the Policy Space and Business Donations to Political Parties. Political Studies, 68(2), pp. 293-310. DOI: 10.1177/0032321719841243

Mudde, C. (2007) The Populist Radical Right in Europe. Cambridge: Cambridge University Press. DOI: 10.1017/CBO9780511492037

Mudde, C. \& Rovira, C. (2017) Populism: a very short introduction. Oxford: Oxford University Press. DOI: 10.1093/actrade/9780190234874.001.0001

Newman, M. E. J. (2010) Networks: an introduction. Oxford, Nova York, Oxford UniversityPress.

Rubio, D. F. (2005) Financiamento de campanhas: fundos públicos versus fundos privados. Novos Estudos CEBRAP, s/v(73), pp.6-16. DOI: 10.1590/S0101-33002005000300001

Samuels, D. (2001) Money, elections and democracy in Brazil. Latin American Politics and Society, 43(2), pp.27-48. DOI: $10.2307 / 3176970$ 
Scarrow, S. (2006) Party subsidies and freezing of party competition: Do cartel mechanisms work? West European Politics, 29(4), pp.619-639. DOI: 10.1080/01402380600842148

Scarrow, S. (2007) Political finance in comparative perspective. Annual Review Political Science, 10, pp.193-210. DOI: 10.1146/annurev.polisci.10.080505.100115

Scott, J. (2000) Social network analysis: a handbook. London: SAGE.

Schmitt, R. (2000) Partidos políticos no Brasil: (1945-2000). Rio de Janeiro: Zahar.

Speck, B. (2007) O financiamento de campanhas eleitorais. In: L. Avritzer \& F. Anastasia (orgs) Reforma política no Brasil. Belo Horizonte: Editora da UFMG, pp.153-158.

Speck, B. (2011) Objetivos e estratégias do setor privado no financiamento das campanhas eleitorais: um modelo de análise baseado em dados da campanha no Brasil em 2010. In: Conferência IPSA-ECPR "Whatever happened to North-South? São Paulo.

Speck, B. \& Mancuso, W. (2013) O que faz a diferença? Gastos de campanha, capital político, sexo e contexto municipal nas eleições para prefeito de 2012. Cadernos Adenauer, 14(2), pp.109-126.

Wasserman, S. \& Faust, K. (1994) Social network analysis: methods and applications. Cambridge: Cambridge University Press. DOI: 10.1017/CBO9780511815478

\section{Artigos e jornais}

Ex-assessor e planilha implicam Bolsonaro e ministro em Caixa 2 (2019) Folha de São Paulo. São Paulo, 6 de Out. Disponível em: <https://www1.folha.uol.com.br/poder/2019/10/ex-assessor-e-planilha-implicam-bolsonaro-e-ministro-em-caixa-dois.shtml>. Acesso em: 26 de Ago. 2021.

Incubation of the far right: the PSL funding network in the 2018 elections.

Keywords: Bolsonaro; far right; parties; campaign financing; social networks.

ABSTRACT Introduction: The article analyzes the income network of the Social Liberal Party (PSL) electoral campaigns in 2018. Considering the outstanding success of this party in that electoral process, selecting as an object of study the campaigns of the party that won the major position in the federal executive is justified. Materials and methods: We mobilized the Social Networks Analysis to analyze the data provided by candidates and party bodies linked to the PSL to the Superior Electoral Court and, in doing so, we map the complex network of relationships established among the agents mobilized in that year's campaign. This method allows the identification of central actors within the network, and groups formed therein. Results: The empirical result of the research identifies significant rates of electoral success in situations of lower financial volume, corroborating the interpretation of the prominent role that ideological aspects played in the 2018 elections; in addition to identifying the detachment of the presidential campaign in relation to party bodies. Discussions: It was possible to problematize the conditions of electoral success in such an exceptional political situation, as well as to visualize characteristics of the far right in this situation.

This is an Open Access article distributed under the terms of the Creative Commons Attribution Non-Commercial License which permits unrestricted non-commercial use, distribution, and reproduction in any medium provided the original work is properly cited. 